\title{
Modeling the Expansion of Prosopis Juliflora and Determining its Optimum Utilization Rate to Control its Invasion in Afar Regional State of Ethiopia
}

\author{
Surafel Luleseged Tilahun, and Araya Asfaw \\ Computational Science Program, Science Faculty \\ Addis Ababa University, 1176 A. A., Ethiopia \\ E-mail:surafelaau@yahoo.com \\ Physics Department, College of Natural Science, \\ Addis Ababa University, 1176, A. A., Ethiopia \\ E-mail: araya@phys.aau.edu.et
}

\begin{abstract}
Prosopis juliflora is an alien invasive tree species which is expanding at an alarming rate in the Horn of Africa region. In this paper a mathematical model is developed to estimate the rate of expansion in the Afar region of Ethiopia based on the coverage obtained with GIS analysis from the year 2000 satellite image for the region. The exponential model estimates that the tree species has been expanding at a rate of 50,000 hectares per year in the last ten years in the Afar region. The model further projects, if the tree species is used for productive uses such as energy and consumed at a rate of 90,000 hectares per year, the invaded land can be restored effectively in 15 years time. Furthermore, the model proposes that after the end of the 15 years, Prosopis can be contained within 200,000 hectares and provide 26,000 hectares of wood per annum sustainably for productive uses.
\end{abstract}

Keywords: Modeling, Prosopis juliflora, optimum utilization, Afar regional state. 


\section{Introduction}

The Prosopis juliflora which is native to Central America has spread globally over the last 200 years. Currently, it is found in various semi-arid and arid regions of India and Pakistan, Australia and the Pacific, several countries in Africa, the Arabic Peninsula, and the Middle East [1,2]. According to Pasiecznik et al [2] the precise history of its introduction is not definite. However, introductions into Senegal in 1822, South Africa around 1880 and Egypt around 1900 have been documented. Less clear is the establishment of Prosopis juliflora in other countries of Eastern Africa, mostly around the 1980s, possibly through livestock migration from Sudan or southern Africa or by traders, perhaps from India [3].

In Ethiopia, there are about 22 invasive alien species [4]. Among these, the major ones are, mesquites (Prosopis juliflora), parthenium (Parthenium hysterophorus), water hyacinth (Eichhornia crassipes) and lanthanum (Lantana camara) [5]. Of these, Prosopis juliflora that is believed to have been introduced to Ethiopia during the establishment of irrigation development in the Afar (Middle Awash) as wind break, shade and shelter [6] is extremely aggressive. In the process, it causes environmental damage and threatens the livelihood of the pastoralist community due to the reduced grazing potential of pastures and range. On the whole, it adversely affects sustainable land use since the specie has covered a significant part of pastor and arable land. Worse, it is migrating to other parts of the country and various studies have revealed that the invasive species affects food security of the population directly and/or indirectly because the plant stifles indigenous plant species, while at the same time competes for and diminishes the productivity of crop land with reduced production [5,7]. While it offers a potential option for agro forestry [8] and many other purposes [9], but because its negative impact from the invasion outweigh its potential uses, residents consider Prosopis as a menace to their livelihood [10]. Apart from Ethiopia Prosopis has similar effect in neighboring countries such as Eritrea, [3], and Kenya [11].

The other dimension is that several studies have unequivocally underscored that Prosopis juliflora offers many uses [2]. Therefore, if its expansion is controlled and harvested sustainably, it can meet the timber and energy needs of the local community without the adverse effect experienced currently. With this in perspective, the aim of this paper is to estimate the rate of expansion of Prosopis juliflora in the Afar region of Ethiopia using mathematical modeling based on the available data of its coverage in one of the districts (Amibara) that spans over twenty years and the result of GIS analysis of Landsat ETM+ 2000 of Afar region. Further, the paper proposes a way to effectively reverse the trend through its sound utilization to eventually control the invasive species within fifteen years. 


\section{The Approach}

Mathematical modeling is used to estimate the rate of Prosopis juliflora expansion in the Afar region of Ethiopia based on available data that spans over twenty years in one of the districts (Amibara). For the modeling purpose a secondary data from Engida [12] is used. According to Engida [12], the coverage of Prosopis juliflora in one of the districts of Afar national regional state in three different year is estimate. First we model the expansion rate using least square method on the secondary data.

The model then extrapolated to Afar region using the result of a GIS analysis project conducted on the Landsat ETM 2000+ satellite image of Afar region under HOAREC $/ \mathrm{N}^{1}$ of Addis Ababa University [13]. The GIS analysis was done on Landsat ETM 2000+ on Amibara district of Afar regional state. In the project land use classification was performed by digital image classification and prior data from the field work was incorporated. And after doing a band selection, the coverage of Prosopis was calculated using ArcGIS software and ERDAS IMAGINE.

After the modeling was done, the optimum utilization rate is discussed. Different mathematical concepts are used. And different utilization scenarios are discussed with a numerical example given at the end.

The next section is devoted to the modeling of the expansion in Amibara district and extrapolating it to Afar National Regional State. Section 4 discusses the optimum utilization rate for constant consumption and variable consumption scenarios, followed by a numerical example as a case study. At last a discussion on the limitation of the study, future work and conclusion will be given.

\section{Modeling the Expansion Rate}

The mathematical model used in this paper is based on the least square method (LSM). The method assumes that the best-fit curve of a given type is the curve that has the minimal sum of the deviations squared (least square error) from a given set of data [14]. Suppose the data points $\left(x_{i}, y_{i}\right)$ for $i=1,2, \ldots n$, is given, where $x$ and $y$ are the independent and dependent variables, respectively. The fitting curve $f(x)$ has the deviation (error), $\left(y_{i}-f\left(x_{i}\right)\right)$. According to the least square method, the condition for selecting the best fitting curve is that the sum of the square error should be minimum. Mathematically, this is expressed as follow.

$\sum_{i=1}^{n}\left(y_{i}-f\left(x_{i}\right)\right)^{2}$ is minimum.

\footnotetext{
${ }^{1}$ Horn of Africa Regional Environment Center and Network
} 
For instance, if the fitting curve is a polynomial of order $k$, so that:

$$
f(x)=a_{0}+a_{1} x+a_{2} x^{2}+\ldots+a_{k} x^{k}
$$

Then,

$$
\min \sum_{i=1}^{n}\left(y_{i}-f\left(x_{i}\right)\right)^{2}=\min \sum_{i=1}^{n}\left(y_{i}-\left(a_{0}+a_{1} x_{i}+a_{2} x_{i}{ }^{2}+\ldots+a_{k} x_{i}{ }^{k}\right)\right)^{2}
$$

This is unconstrained optimization problem with the objective function given as:

$$
g\left(a_{0}, a_{1}, \ldots, a_{k}\right)=\sum_{i=1}^{n}\left(y_{i}-\left(a_{0}+a_{1} x_{i}+a_{2} x_{i}{ }^{2}+\ldots+a_{k} x_{i}{ }^{k}\right)\right)^{2}
$$

Hence the optimizer needs to satisfy:

$$
\frac{\partial g}{\partial a_{i}}=0, \text { for } i \in\{0,1,2, \ldots ., k\}
$$

From these there will be $k+1$ equations and a solution can easily be found.

\subsection{Expansion rate in Amibara District}

According to Engida [12] the coverage of Prosopis juliflora in Amibara district shown in Table 1.

Table 1: Prosopis juliflora coverage in Amibara District

\begin{tabular}{ccc}
\hline Year & Hectares & Percentage \\
\hline 1986 & 768.8 & 0.2 \\
2001 & $3,848.6$ & 1.1 \\
2007 & $11,578.7$ & 3.4 \\
\hline
\end{tabular}

Let the dependent variable, $y(x)$, represent the Prosopis coverage in thousands of hectares (khe) and the dependent variable $x$ represent the time in years. For simplicity, let $x=1$ represent the year 1986, and a unit in $x$ represent 5 years. Thus $x=2$ means 1991, $x=4$ means 2001 and $x=5.2$ means 2007. Figure 1 shows that Prosopis juliflora coverage is increasing over the years. From Figure 1, a number of possible growth scenarios can be proposed. 


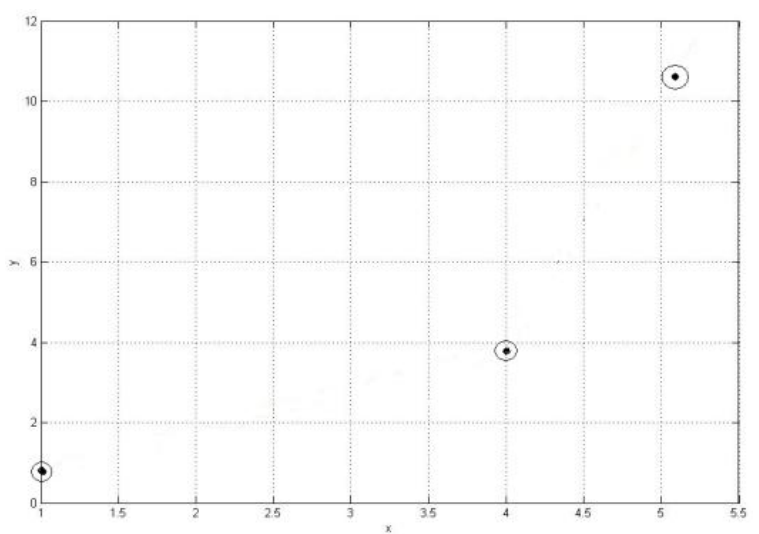

Figure 1: Prosopis juliflora coverage, $y$, over years, $x$

It is quite clear that Prosopis will keep on expanding until a certain level a level from which no further increment is possible. But our interest lies before reaching that level. Hence we are considering an increasing scenario only. There for our interest is to model the increasing coverage only.

For the data points shown in Fig 1, many possible increasing fits can be suggested. Matlab software and least square method are used to find the best fit of the data set. The curve fitting tool box of Matlab has a wide range of function categories to fit for a given data set. For our data set we try to fit all possible fits in the tool box and find the best exponential and logarithmic fit using least square method. The best fit for different types of mathematical functions from the Matlab tool box are is summarized below:

Table 2: Seven different models

\begin{tabular}{|c|c|c|}
\hline \multicolumn{3}{|c|}{ Polynomial fit } \\
\hline 1 & Linear Polynomial & $\mathrm{y}_{\mathrm{L}}(\mathrm{x})=2.276 \mathrm{x}-2.341$ \\
\hline 2 & Quadratic Polynomial & $\mathrm{y}_{\mathrm{Q}}(\mathrm{x})=1.289 * \mathrm{x}^{\wedge} 2-5.42 * \mathrm{x}+4.899$ \\
\hline \multicolumn{3}{|c|}{ Rational fit } \\
\hline 3 & Rational 1 & $\mathrm{y}_{\mathrm{R} 1}(\mathrm{x})=(2.463 \mathrm{e}+004) /(\mathrm{x}+4561)$ \\
\hline 4 & Rational 2 & $\begin{array}{l}\mathrm{y}_{\mathrm{R} 2}(\mathrm{x})=(6407 * \mathrm{x}-6576) /(\mathrm{x}+ \\
2812)\end{array}$ \\
\hline \multicolumn{3}{|c|}{ Sum of sin functions fit } \\
\hline 5 & Sum of sin function & $\begin{array}{l}\text { YSSF }(x)=568.6 * \sin (0.004003 * x- \\
0.004115)\end{array}$ \\
\hline \multicolumn{3}{|c|}{ Exponential fit } \\
\hline 6 & Exponential & $\mathrm{y}_{\mathrm{E}}(\mathrm{x})=0.3882 \mathrm{e}^{\wedge} 0.6248 \mathrm{x}$ \\
\hline \multicolumn{3}{|c|}{ Logarithmic fit } \\
\hline 7 & Logarithm & $\mathrm{y}_{\mathrm{Ln} 1}(\mathrm{x})=\ln (12614.4989 * \mathrm{x})$ \\
\hline
\end{tabular}


Among the given fits in table 2, some are in contrary with the reality and some with large deviation from the data. Hence, a realistic model with minimum error needs to be chosen to represent the scenario.

\subsection{Analysis of the models}

The seven models are plotted in one graph as shown in Fig 2. It is quite easy to see from the graph that some of the function doesn't represent the situation well.

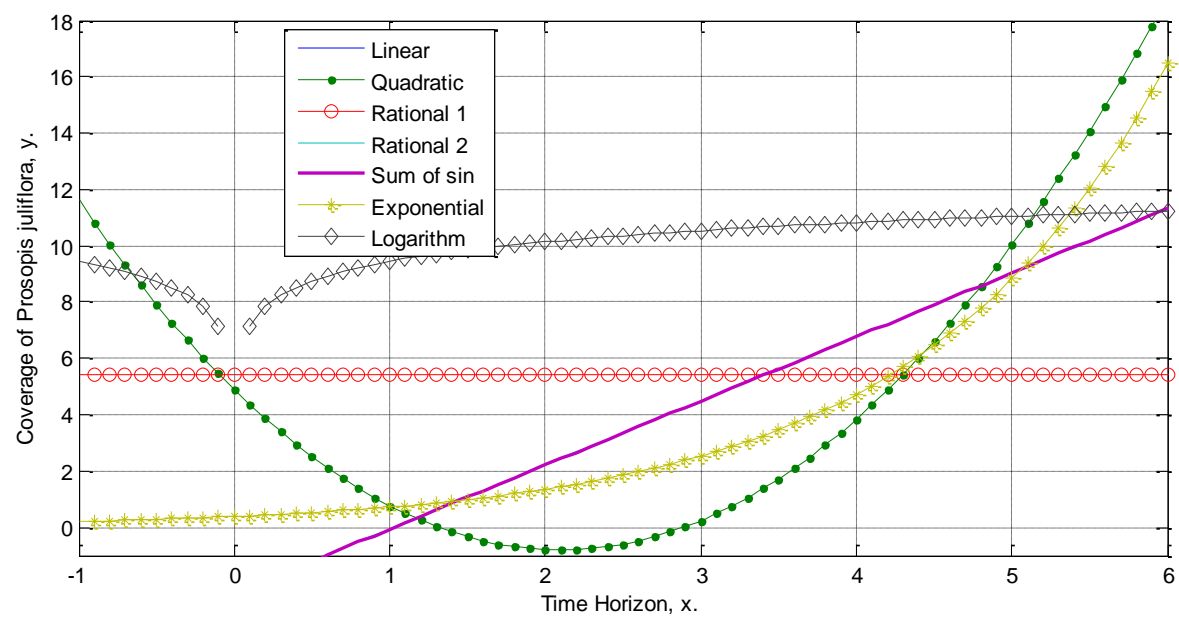

Figure 2: The models

For comparison purpose the square sum error (SSE) of each model is calculated. For a given model, say $\mathrm{y}(\mathrm{x})$, the square some error can be calculated in the three data points as follows:

$$
S S E=\sum_{i=1}^{3}\left(y\left(x_{i}\right)-y_{i}\right)^{2}
$$

The SSM of each model is presented in table 3.

Table 3: Error Comparison of the models

\begin{tabular}{cccc|c}
\hline $\mathrm{x}$ & 1.0 & 4.0 & 5.2 & \\
$\mathrm{y}$ & 0.7688 & 3.8486 & 11.5787 & $\mathrm{SSE}$ \\
\hline $\mathrm{y}_{\mathrm{L}}(\mathrm{x})$ & -0.0643 & 6.7646 & 9.4962 & 13.5342 \\
$\mathrm{y}_{\mathrm{Q}}(\mathrm{x})$ & 0.7680 & 3.8430 & 11.5696 & 0.00012 \\
$\mathrm{y}_{\mathrm{R} 1}(\mathrm{x})$ & 5.3989 & 5.3954 & 5.3940 & 62.0816 \\
$\mathrm{y}_{\mathrm{R} 2}(\mathrm{x})$ & -0.0601 & 6.7656 & 9.4918 & 13.5510 \\
$\mathrm{y}_{\mathrm{SSF}}(\mathrm{x})$ & -0.0637 & 6.7645 & 9.4955 & 13.5349 \\
$\mathrm{y}_{\mathrm{E}}(\mathrm{x})$ & 0.7251 & 4.7255 & 10.0014 & 3.2587 \\
$\mathrm{y}_{\mathrm{Ln} 1}(\mathrm{x})$ & 9.4426 & 10.8289 & 11.0913 & 124.1969 \\
\hline
\end{tabular}


In the given duration the linear, the rational 2 and the sum of sin models almost overlap. Since the linear model over simplify the situation and is with high SSE we reject the linear model with rational 2 and the sum of sin model, which models the scenario in almost in the same way as the linear model. Similarly, the logarithmic model and the rational 1 model have a big deviation from the data set. Even though the quadratic model has a smallest SSE it doesn't represent the reality well. It suggests that Prosopis juliflora coverage decreases to negative value from $1981(x=0)$, onwards and suddenly rises up. Hence we are left to compare only power 1 , power 2 , rational 2 and exponential model.

Hence, the exponential model describes the expansion of Prosopis juliflora in Amibara district with minimum error and is in agreement with the reality. The expansion in Amibara district therefore can be expressed as an exponential function with an appropriate error bounds as in Equation 6.

$$
a e^{b x}-E_{1}(x) \leq y(x) \leq a e^{b x}+E_{2}(x)
$$

In the above equation, $y(x)$ is the coverage and $E_{i}(x)$ is the error function.

The error function for the exponential mode can be modeled as either a constant function, by taking the maximum absolute error, as a linear or any other model. Here exponential model is used with the largest absolute error as error bounds, $E_{1}(x)=E_{2}(x)=1.5773$. The value of $a=0.3882$ and $b=0.6284$. Therefore the exponential model which describes Prosopis juliflora expansion in Amibara district of Afar regional State of Ethiopia is illustrated on Figure 3.

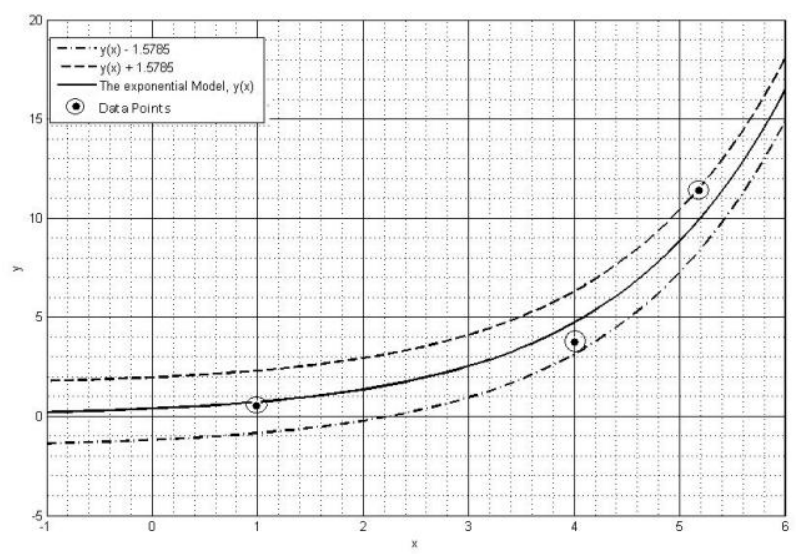

Figure 3: Error bands for the exponential model

The model projects the Prosopis coverage by 2010 in the district is $14,550 \pm$ 1,577 hectares. 


\subsubsection{Extrapolating the model to Afar National Regional State}

Extrapolation is prediction outside the given data coverage [13]. Hence, the model which simulates the expansion of Prosopis juliflora in Amibara district can be extrapolated to the rest of the Afar Regional State. Such extrapolation assumes that the same environmental conditions and the means of propagation present in Amibara also prevail throughout the Afar region. With these assumptions, the expansion rate in the region can be determined by shifting the time frame backward. From satellite data analysis of Landsat ETM+ of 2000 the coverage of Prosopis juliflora in Afar National Regional State in year 2000 was 212.82 thousand of hectares Sheferaw [13].

Based on the model developed, one can project how long it will take for Prosopis to cover 212.82 thousand hectares of land in Amibara district. The above coverage of Prosopis juliflora will be attained at some time $x$ '.

Let:

$$
y\left(x^{\prime}\right)=\alpha=a x^{b}+c=212.82
$$

From this equation $15 x^{\prime}=9.8$, which corresponds to year 2030

If the time horizon is shifted forward so that the year 2030 corresponds to year 2000 then,

$$
y(x)=a e^{b(x+10)}
$$

Hence, the general solution for the Prosopis propagation in the Afar region can be expressed as

$$
y(x)=y_{0} e^{b x}
$$

where $y_{0}=a e^{10 b}$.

At $\mathrm{x}=0$ which corresponds to year 2000, the Prosopis coverage is $\mathrm{y}_{-} 0=226.0988$ khe. Using Equation 17, the Prosopis coverage in 2010, $(\mathrm{x}=2)$ is 548,441 hectares, which is in good agreement as estimated by others [16].

\section{Optimum utilization of Prosopis juliflora}

The availability of such large amount of Prosopis juliflora can attract investment which requires sustainable supply and access. On the other hand, the local community is primarily interested in reclaiming the invaded land and therefore prefers eradication. Finding a compromise hence is a challenge. 


\subsection{Constant Utilization}

Here utilization of Prosopis juliflora at constant rate is considered. Assume each year $H$ amount of hectares Prosopis is consumed. Let the coverage of the Prosopis which will produce $H$ thousands of hectares be $y^{\prime}$.

If

$$
y\left(x^{*}\right)=y^{\prime}
$$

Then

$$
y\left(x^{*}+0.2\right)-y^{\prime}=H
$$

Suppose the coverage of Prosopis juliflora at the beginning of the project is $y_{c}$.

$$
y_{c}-y^{\prime}=k
$$

The project will consume $H$ amount of Prosopis per year beginning from the first year it is initiated. But the excess amount will continue to expand. Controlling or eradicating Prosopis therefore has two parts as shown in Figure 7, the part which will be used by the investment, $y(x)$, and the excess part which the investment is not going to use, $k(x)$.

$$
\frac{d y(t)}{d t}=H
$$
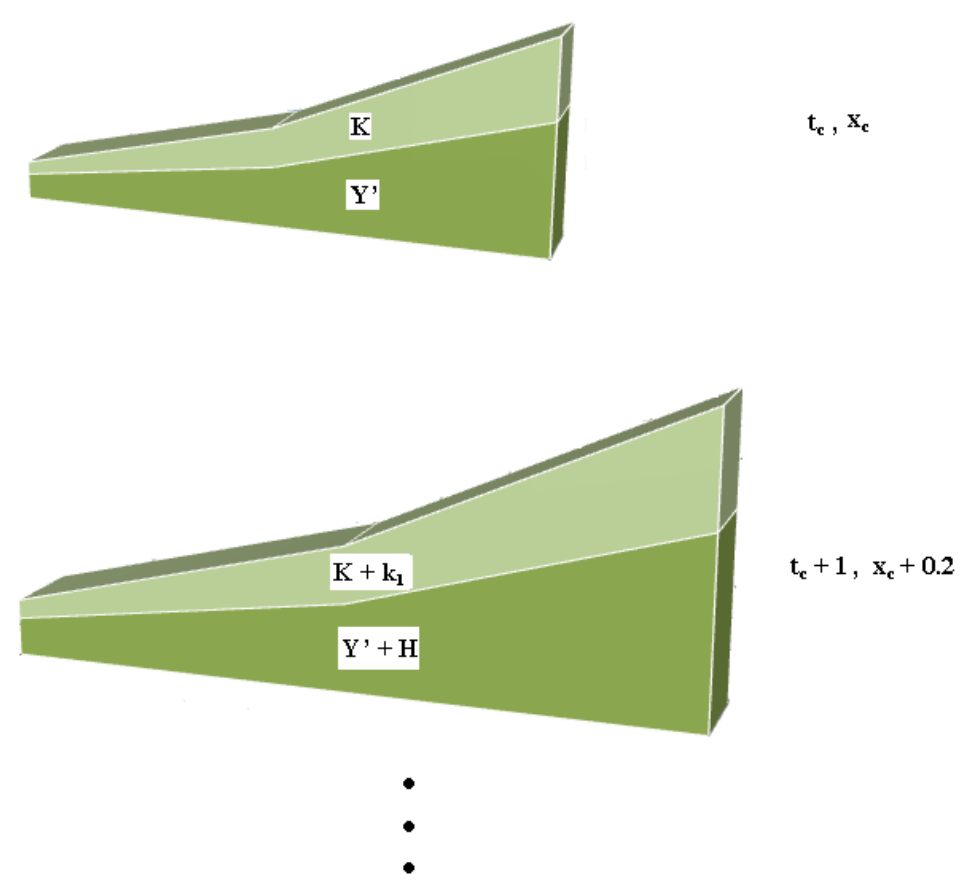

Figure 4: The invasion of Prosopis juliflora from the beginning of the investment onwards 
It is, therefore, necessary to determine a rate for the control or eradication of the excess amount, say $f(x)$. Suppose one targets to control the invasion at the time $x=x$ " starting utilization at $x=x_{c}$. One can construct a sequence of numbers by taking the difference of $k(x)$ and $f(x)$ (as shown in Figure 5):

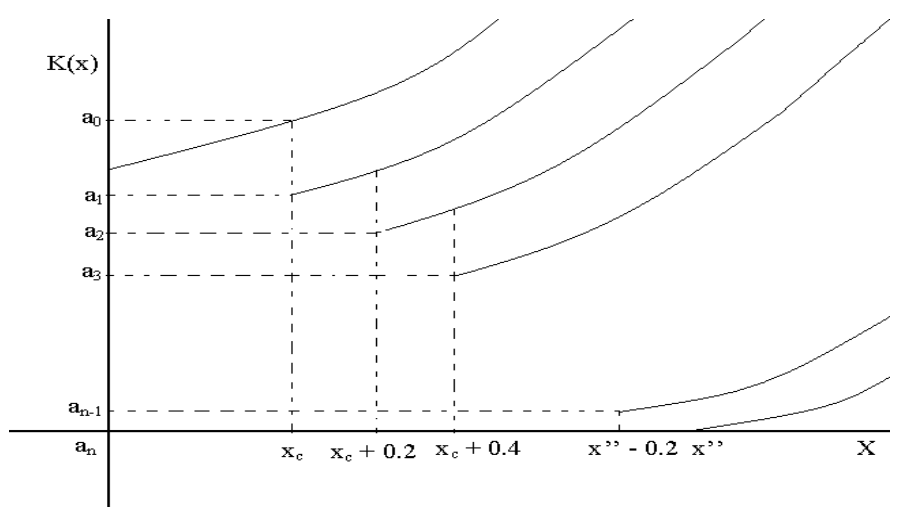

Figure 5: The expansion of the excess Prosopis juliflora and its diminishing rate in the case of constant utilization

If one targets to control the invasion in 15 years the following sequence can be generated:

$$
\begin{aligned}
& \mathrm{a}_{0}=\mathrm{k}\left(\mathrm{x}_{\mathrm{c}}\right) \\
& \mathrm{a}_{1}=\mathrm{k}\left(\mathrm{x}_{\mathrm{c}}\right)-\mathrm{f}\left(\mathrm{x}_{\mathrm{c}}\right) \\
& \mathrm{a}_{2}=\mathrm{a}_{1} \mathrm{e}^{(0.2)(0.6248)}-\mathrm{f}\left(\mathrm{x}_{\mathrm{c}}+0.2\right) \\
& \cdot \\
& \cdot \\
& \mathrm{a}_{\mathrm{n}}=\mathrm{a}_{\mathrm{n}-1} \mathrm{e}^{(0.2)(0.6248)}-\mathrm{f}\left(\mathrm{x}_{\mathrm{c}}+0.2(\mathrm{n}-1)\right)
\end{aligned}
$$

Generally,

$$
a_{n}=a_{n-1} e^{0.2 b}-f\left(x_{c}+0.2(n-1)\right), \text { for } i \in\{1,2, \ldots, n\}
$$

At $\mathrm{x}=\mathrm{x},, n=5\left(x^{\prime \prime}-x_{c}\right)$

Hence it is possible to determine $f(x)$. Furthermore $a_{5\left(x^{*}-x_{c}\right)}=0$ and let us define $g(x)$ as:

$$
g(x)=\left\{\begin{array}{l}
f(x), \text { for } x \in\left[x_{c}, x "\right] \\
0, \text { for } x>x "
\end{array}\right.
$$


The optimum utilization rate, $U(x)$, therefore is the sum of the constant rate, $H$, and the variable rate, $U^{\prime}(x)=g(x)$ as defined by Equation 16 .

$$
U^{\prime}(x)=H+U(x)
$$

\subsection{Variable Utilization}

In reality, however, any investment or project starts with some initial utilization rate and reaches gradually at some final constant rate. Let the utilization rate be $C(x)$ for $x$ in $\left[x_{c}, x^{\prime \prime}\right]$, where $x_{c}$ is the year the project is initiated and $x^{\prime \prime}$ is the target year the Prosopis expansion is controlled and harvested at a constant rate $H$. The utilization rate for such scenario is expressed by Equation 17. This is plotted on Figure 6.

$$
U_{f}(x)=\left\{\begin{array}{c}
C(x), \text { for } x \in\left[x_{c}, x "\right] \\
H, \text { for } x>x^{\prime \prime}
\end{array}\right.
$$

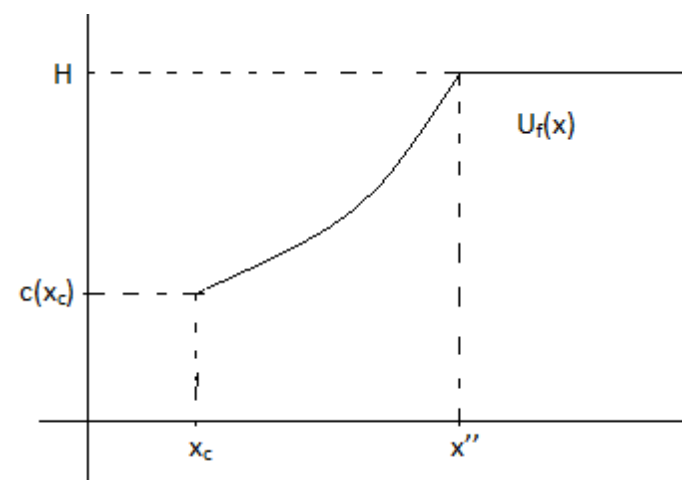

Figure 6: Variable utilization

So as to control the expansion effectively at the time $x=x^{*}$, in addition to $C(x)$ the excess amount ought to be consumed. Depending on $x^{*}$ there are three possible scenarios to consider. The first one is when $x^{*}<x^{\prime \prime}$, the second one when $x^{*}=x^{\prime \prime}$ and the third when $x^{*}>x^{\prime \prime}$. In all cases the rate of utilization of the excess amount, $f(x)$ ought to be determined.

a) The first case is to control the expansion when $x^{*}>x^{\prime \prime}$. If $x^{*}>x^{\prime \prime}, f(x)$ can be determined using the constant utilization case discussed in the previous section where $x^{\prime \prime}<x<x^{*}$.

Hence, to determine the rate of utilization, $f(x)$, of the excess when $x=x^{\prime \prime}$ and onwards, one can define $g(x)$ which describes the rate of utilization 


$$
g(x)=\left\{\begin{array}{c}
0, \text { for } x \in\left[x_{c}, x "\right] U\left\{x \mid x>x^{*}\right\} \\
f(x), \text { for } x \in[x ", x *]
\end{array}\right.
$$

Hence the utilization rate, $U(x)$, will be the sum of the variable utilization rate, $C(x)$, and the utilization rate of the excess amount, $g(x)$.

$$
U(x)=U_{f}(x)+g(x)
$$

b) The second case is to control the expansion at $x=x^{\prime \prime}$. Here, we need to determine the utilization rate of the excess amount, $f(x)$, such that the coverage at $x=x^{\prime \prime}$ produces $H$ amount of Prosopis afterwards. Hence it is possible to construct a sequence of numbers $\left\{b_{i}\right\}$ as shown in Figure 7.

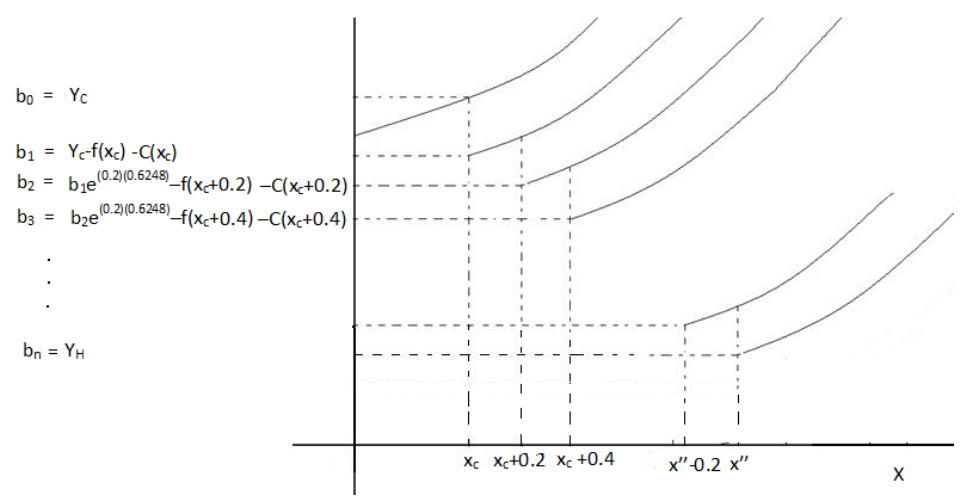

Figure 7: utilization of the excess amount in variable utilization until $\mathrm{x}=\mathrm{x}$,

Let

$$
\begin{aligned}
& b_{0}=Y_{c} \\
& b_{1}=Y_{c}-f\left(x_{c}\right)-C\left(x_{c}\right) \\
& b_{2}=b_{1} e^{0.2(0.6248)}-f\left(x_{c}+0.2\right)-C\left(x_{c}+0.2\right) \\
& b_{3}=b_{2} e^{0.2(0.6248)}-f\left(x_{c}+0.4\right)-C\left(x_{c}+0.4\right) \\
& \cdot \\
& \cdot \\
& \cdot \\
& b_{n}=b_{n-1} e^{0.2(0.6248)}-f\left(x_{c}+0.2(n-1)\right)-C\left(x_{c}+0.2(n-1)\right)
\end{aligned}
$$


Generally

$b_{i}=b_{i-1} e^{0.2 b}-f\left(x_{c}+0.2(i-1)\right)-C\left(x_{c}+0.2(i-1)\right)$

If the project targets to control the expansion in 15 years time then at $x=x^{\prime \prime}$ $n=5\left(x^{\prime \prime}-x_{c}\right)$. The condition to be met is:

$$
b_{5\left(x^{\prime \prime}-x_{c}\right)}=Y_{H}
$$

Furthermore, the rate of utilization of the excess amount, $f(x)$, can be determined with the following definition of $g(x)$

$$
g(x)=\left\{\begin{array}{c}
f(x), \text { for } x \in\left[x_{c}, x^{\prime \prime}\right] \\
0, \text { for } x>x
\end{array}\right.
$$

Hence, the optimum utilization rate to control the expansion until $x=x^{\prime \prime}$ will be:

$$
U(x)=U_{f}(x)+g(x)
$$

c) The third case is to control the expansion for $x^{*}<x^{\prime \prime}$; if there is a need to consume the extra coverage at $x=x_{k}$ where $x_{c}<x_{k}<x^{\prime \prime}$. Here one needs to determine the rate of utilization of the excess amount, so that after when $x$ reaches $x_{k}=x$ without further utilization the expansion will be under control. In such a case one can consider two sequences of numbers, as shown in Figure 8. 


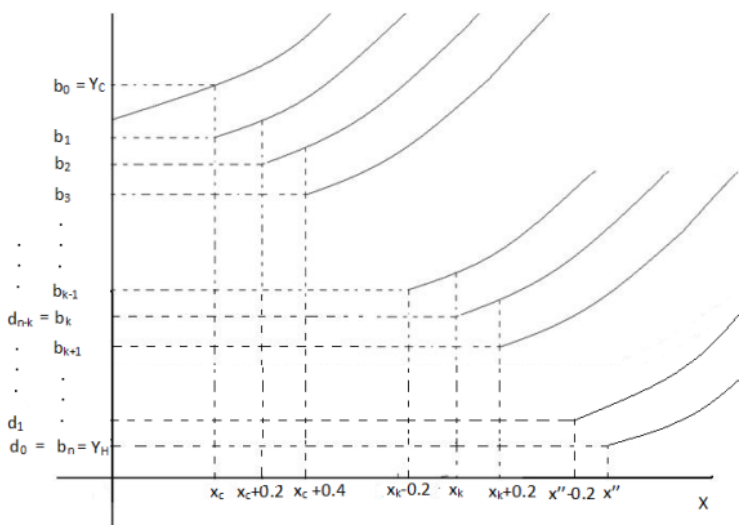

Figure 8: of the excess amount in variable utilization before $\mathrm{x}=\mathrm{x} "$

The first sequence is $\left\{b_{i}\right\}$, as of in the previous scenario:

$b_{0}=Y_{c}$

$b_{1}=Y_{c}-C\left(x_{c}\right)-f\left(x_{c}\right)$

$b_{2}=b_{1} e^{0.2 \beta}-C\left(x_{c}+0.2\right)-f\left(x_{c}+0.2\right)$

$b_{i}=b_{i-1} e^{0.2 \beta}-C\left(x_{c}+0.2(i-1)\right)-f\left(x_{c}+0.2(i-1)\right)$

Suppose that Prosopis is harvested at a rate of $C(x)$ beyond $x_{k}$ since there is no excess then the coverage at an arbitrary time will be:

$y(x+0.2)=y(x) e^{0.2 b}-C(x) \rightarrow y(x)=(y(x+0.2)+C(x)) e^{2 b}$

In such a case, it is possible to generate the following sequence of numbers $\left\{d_{i}\right\}$

$d_{0}=Y_{H}$

$d_{1}=\left(d_{0}+C(x "-0.2)\right) e^{-0.2 \beta}$

$d_{2}=\left(d_{1}+C(x-0.4)\right) e^{-0.2 \beta}$

$d_{i}=\left(d_{i-1}+C(x-0.2 i)\right) e^{-0.2 \beta}$

These two sequence of numbers need to have a common intersection at $x=x_{k}$, with the following condition $f(x)$ can be determined provided: 


$$
b_{k}=d_{n-k}
$$

Hence, once $f(x)$ is determined, the utilization rate for the excess amount will be:

$$
g(x)=\left\{\begin{array}{c}
f(x), \text { for } x \in\left[x_{c}, x_{k}\right] \\
0, \text { for } x>x_{k}
\end{array}\right.
$$

The utilization rate therefore will be

$$
U(x)=U_{f}(x)+g(x)
$$

\section{Numerical Example}

Consider a case in which there is a target of reducing the coverage to 200 thousand of hectares from the coverage of 548,441 hectares until the year 2025. It is clear that 200 thousands of hectares of Prosopis will be 220, 751 hectares within a year. It means it will produce 20, 751 hectares per year. Furthermore, consider an investment with constant utilization $\mathrm{H}$ of 20,751 hectares. Since the current coverage is 548,441 hectares and the target is to reduce it to 200,000 hectares by year 2025, there is an excess amount that needs to be consumed at some rate. This rate should ensure achieving the target. Suppose the utilization of the excess amount is a constant function, then

$$
f(x)=\left\{\begin{array}{l}
B, \text { for } x \leq 2025 \\
0, \text { for } x>2025
\end{array}\right.
$$

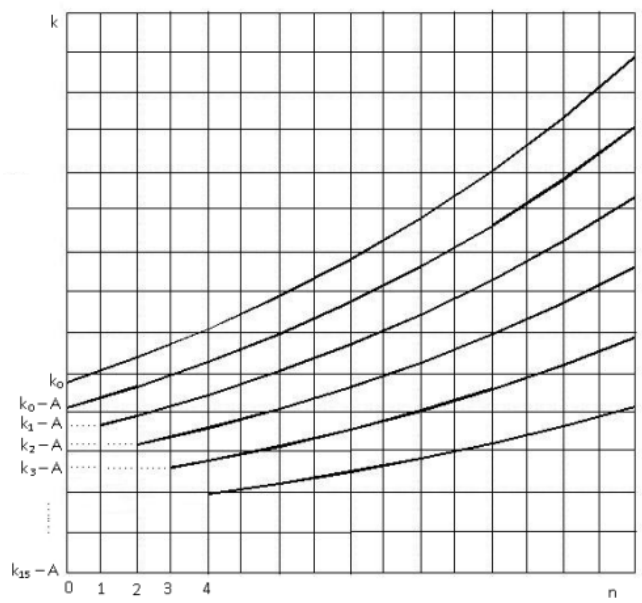

Figure 9: Case Study

As shown in Figure 9, one expect a sequence of numbers where 


$$
k_{i}=k_{(i-1)} e^{(0.2 b)}-A
$$

For $i>1$ with $k_{0}=700.2003, k_{1}=k_{0}-A$ and $A=H+B$ as shown in Figure 9. The condition to be met is $k_{16}=200$. The $i^{\text {th }}$ term of the sequence $\left\{k_{i}\right\}_{i=0}^{16}$ can be expressed as:

$$
k_{i}=k_{0} \mathrm{e}^{(\mathrm{i}-1) \mathrm{b}}-\mathrm{A} \sum \mathrm{e}^{(\mathrm{j}-1) \mathrm{b}}, \text { for } i>1
$$

The condition $k_{16}=200$ gives a constant $B=64.3434$. Hence, from the year 2010 onwards the utilization rate will be:

$$
U(x)=H+f(x)=26.7126+f(x)
$$

The utilization rate for the case can be written as:

$$
U(x)=\left\{\begin{array}{c}
90.9634, \text { for } x \in[2010,2025] \\
26.62, \text { for } x>2025
\end{array}\right.
$$

Therefore, on the basis of the mathematical model, by the end of year 2025, Prosopis can be controlled within 200 thousands of hectares and produces 26.62 hectares sustainably.

\section{Discussion and Conclusion}

In this paper the modeling of the expansion of Prosopis juliflora is modeled using a secondary date on Amibara district. For the modeling purpose the curve fitting tool box of Matlab software and least square method are used. The scenario has been modeled using seven different models ranging from polynomial, rational, sum of sin and logarithmic functions. Analysis was done on the models in terms of sum square error and agreement with the reality. Accordingly, exponential model is found to be the best in describing the expansion. The model then extrapolated to afar region as a whole with the assumption that the region has the same vector of propagation as in Amibara district. Once the model is set the optimum utilization rate is discussed depending on both constant and variable consumptions supported by a numerical example at the end.

One of the limitations with the model is that it is modeled from three data sets. Sufficiently enough recorded data were not found. Other vector of propagations like cattle density, land forms (soil type, moisture and salinity condition) is taken to be the same in Afar region as whole with Amibara district. 
In the future it is planned to relax the assumptions and edit the model. For example by taking the cattle density, soil type into consideration. By collecting sufficiently more data point to remodel the model.

\section{Acknowledgements}

The first author would like to acknowledge a support from AMMSI POSTGRADUATE SCHOLARSHIP AWARD.

\section{References}

[1] Harris, P., Pasiecznik, N., Smith, S., Billington, J., \& Ramirez, L. (2003). Differentiation of Prosopis juliflora (Sw.) DC. and P. pallida (H. \& B. ex. Willd.) H.B.K. using foliar characters and ploidy. Forest Ecology and Management , 180 (1-3), 153-164.

[2] Pasiecznik, N., Cruz, G., Felker, P., Tewari, J., Harris, P., Cadoret, K., et al. (2001). The Prosopis juliflora-Prosopis pallida Complex: A Monograph. UK: HDRA Conventry UK

[3] Bokrezion, H. (2008). The Ecological and Socio-economic Role of Prosopis juliflora in Eritrea: An Analytical Assessment within the Context of Rural Development in the Horn of Africa. Johannes Gutenberg-Universität Mainz, am Fachbereich Chemie, Pharmazie und Geowissenschaften. Johannes Gutenberg-Universität Mainz. http://ubm.opus.hbznrw.de/volltexte/2009/2066/pdf/diss.pdf. Accessed April 5th, 2010.

[4] United Nations Environmental Program (2008). Invasive alian species in Africa. The encyclopidia of earth: http://www.eoearth.org/article/Invasive_alien_species_in_Africa. Acceded December 15th 2009.

[5] Admasu, D. (2008). Invasive Plants and Food Security: the case of Prosopis juliflora in the Afar region of Ethiopia. (IUCN, FARM AFRICA). Addis Ababa, Ethiopia. http://cmsdata.iucn.org/downloads/invasive_plants_and_food_security__fin al.pdf. Accessed March 12, 2010

[6] Berhanu, A., \& Tesfaye, G. (2006). The Prosopis Dilemma, Impacts on Dryland Biodiversity and Some Controlling Methods, Journal of Drylands , 1(2), 158-164

[7] Beruk Yiemane(2003). Food Security Situation in the Pastoral Areas of Ethiopia. Oxfam

GB http://www.oxfam.org.uk/resources/learning/pastoralism/downloads/food_se curity_ethiopia.pdf. accessed April 28, 2010.

[8] Sertse, D. (2005). Controlling the spread of Prosopis in Ethiopia by its utilisation. Holetta Agricultural Research Centre. 
http://www.gardenorganic.org.uk/pdfs/international_programme/EthiopiaPro sopisBrief.pdf. Accesed February 23, 2010.

[9] Orwa et al.(2009). Prosopis juliflora. Agroforestry Database 4.0, worldagroforestry http://www.worldagroforestry.org/treedb2/AFTPDFS/Prosopis_juliflora.pdf. Accessed January 10, 2010.

[10] Hailu Shiferaw (2004). Prosopis juliflora: The Paradox of the Dryland Ecosystems, Afar Region, Ethiopia. IBCR. http://www.berfingen.info/akababi/hailu1.htm. Accessed November 29, 2009.

[11] Mwangi, E. and Swallow, B. (2008). Prosopis juliflora invasion and rural livelihoods in the Lake Baringo Area of Kenya. Conservation and Society 6(2), 130-140.

[12] Engida, G. (2008). Spatial and temporal analysis of Prosopis juliflora (SWARZ DC) invasion in Amibara district of Afar region, M.Sc. thesis in the department of Environmental Science, Addis Ababa University, Ethiopia.

[13] Shiferaw H. (2009), The study on the coverage of Prosopis in Afar region using GIS data, internal report under Horn of Africa Regional Environment Center and Network

[14] Frank R. Giordano, William P. Fox, Steven B. Horton and Maurice D. Weir (2009). A first cource in mathematical modeling. Belmont, USA: Cengage Learning.

[15] Sharad S. Johri, Rajendra Rathore (1998): Advanced Business Statistics. New Delhi, India. Atlantic Publisher and Distributer.

[16] Mikias Sissay (2007). Prosopis for Life. Food and Agricultural Organization of the United Nations in Ethiopia (FAO, Ethiopia). Special issue 02(12). 